\title{
Analysis of a Local Factors affecting the Performance of the Photovoltaic Panels
}

\author{
Marek Novak, Pavol Belany, Marek Roch, Peter Bracinik
}

\begin{abstract}
This paper discusses about the influence of local factors on the performance of photovoltaic panels. The factors selected for this analysis are: partial shading of panels due to the device located immediately before the photovoltaic panels, pollution of photovoltaic panels and mechanical damage of photovoltaic panels. These factors are first explained and then are described the possibilities of eliminating these factors. Also, the measurement of the influence of local factors on the performance of the photovoltaic panels and their negative impact on the performance of the photovoltaic panels is presented.
\end{abstract}

Index Terms - photovoltaic panels, renewable sources, pollution, shaded photovoltaic panel.

\section{INTRODUCTION}

Low efficiency is one of the fundamental problem of photovoltaic power plants. In a research of the increasing a photovoltaic panels efficiency were invested a lot of money but the present photovoltaic panels do not reach efficiency more than $25 \%$ with common monocrystalline panels or up to $55 \%$ by multilayer photovoltaic panels [1]. Therefore, any increase in efficiency, which is only $1 \%$, means a significant shift in this area. There are many ways to increase this parameter. One way is to choose such a material of photovoltaic cells, which is better able to use the whole solar spectrum [2]. Another possibility is to focus on the fact that the best efficiency of conversion of solar energy to electrical is achieved by photovoltaic panels when the direction of the rays is perpendicular to the surface of the panel [3]. Due to the unfavorable influence of warming on the efficiency of photovoltaic panels, their cooling seems to be another effective way [4]. Also, the elimination of possible shading and regular cleaning of photovoltaic panels can also be avoided [5], [6]. The possible ways of elimination local factors on the efficiency of the photovoltaic power plant are described in this paper.

This work was supported by Slovak Research and Development Agency under the contract No. APVV-16-0505: The short-term prediction of photovoltaic energy production for needs of power supply of Intelligent buildings - PREDICON

Marek Novák, Department of Power Electrical Systems, University of Žilina, Žilina, Slovakia, 0415132197

Pavol Belány, Department of Power Electrical Systems, University of Žilina, Žilina, Slovakia, 0415132197

Marek Roch, Department of Power Electrical Systems, University of Žilina, Žilina, Slovakia, 0415131521

Peter Braciník, Department of Power Electrical Systems, University of Žilina, Žilina, Slovakia, 0415132164

\section{LOCAL FACTORS THAT AFFECT PHOTOVOLTAIC PANELS PERFORMANCE}

Electricity generation in photovoltaic power plants also brings several problems. Solar radiation falls on the panels only for a limited time. The impact angle is constantly changing. Also the panel temperature affects its performance. However, this study focuses on the influence of another local factors on photovoltaic panels. One of these factors is partial shading of the photovoltaic panel (PV panel). It is often the case that the location of photovoltaic panels on the roofs of buildings is not ideal and the panel is permanently shielded by other equipment. For example, a retrofitted air conditioning on the roof of a building where a photovoltaic power plant has already been installed. Another local factor is the pollution of the panels. The level of pollution differs from location and length of operation. During the operation of the photovoltaic power plant, a layer of impurities of different composition and thickness are deposited on the panels. This will cause a partial decrease in performance. Another significant factor is mechanical damage of the panel. On the photovoltaic panels are often micro cracks, but it can also happen that the impact of the storm, the impact of the contour, the impact of the corners will break the panel. Such damage has a significant impact on the photovoltaic panel performance.

\section{POSSIBILITIES OF REDUCING THE IMPACT OF THE LOCAL FACTORS}

The local factors mentioned in this paper are the most neglected influences that reduce the efficiency of photovoltaic systems. Depending on the state, age and location of the photovoltaic system, it is necessary to check the photovoltaic system and evaluate the solution procedure based on the measurement results. The possible ways are mentioned below.

\section{A. Cleaning of the Photovoltaic Panels}

The neglect of cleaning the PV panels will be interpreted by their lower performance and by shortening the lifetime of the PV panels. Partial rain and wind cleaning of the photovoltaic panels will not completely remove all impurities that are deposited on the surface of the photovoltaic panels. Therefore, there is a situation of permanent pollution of the panel, which leads to a decrease in the efficiency of the conversion of a solar energy to an electric energy. Neither the tilting of the panels will ensure their adequate cleaning with rain and wind. In a cities, dust, grease and various chemical compounds from emissions are deposited on the PV panels (Figure 3.1). In the meadows, photovoltaic panels are polluted by the dust and frequent pollution is caused by bird 
feces. Therefore, a study was carried out to determine the effectiveness of the surface cleaning of photovoltaic panels in 2017 by Milk the Sun GmbH and MeteoControl GmbH. Testing was carried out on a sample of seventeen large landfill sites throughout Germany. All selected PV panels have not been cleaned ever since their initial start-up in 2007 to 2013. The test was subjected to three types of panels, namely polycrystalline, monocrystalline and thin-walled. Each plant was cleaned with an area of $30 \mathrm{~kW}$ and its output was compared to the power of the rest of the plant over a period of seven months. Photovoltaic panels were cleaned only with demineralized water using a rotating brush without the use of chemical agents. The results of the study confirmed that cleaning of photovoltaic panels has an impact on the increase in PV power. Immediately after cleaning, the power of most power plants increased. At some power plants, this increase was up to $5 \%$. In the case of heavily polluted PV plants found, for example, in industrial areas, the power can be increased by $10 \%$ after cleaning. In countries with higher dust levels, the benefits of panel cleaning are of course even more pronounced. The frequency of cleaning depends on the type of panels, the place of placement, the inclination of the panels, Under normal conditions, however, it is advisable to clean the panels twice a year [7].

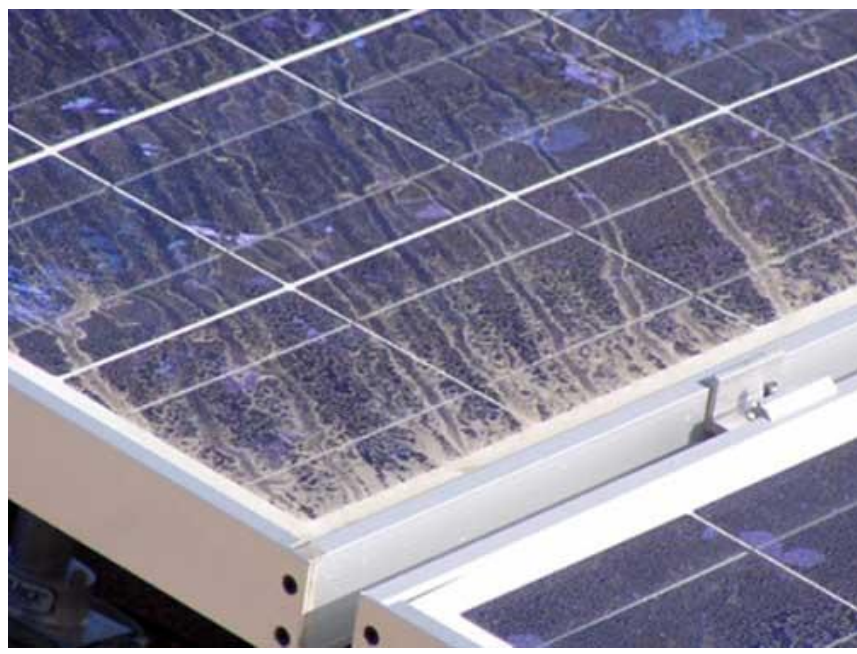

Fig. 3.1. Pollution of the photovoltaic panel

\section{B. Elimination of partial shading of Photovoltaic Panels}

The damping of a part of the photovoltaic panel negatively affects the amount of produced electricity. If only one photovoltaic cell is shielded, all other photovoltaic cells connected to it in series supply only the current supplied by the shielded article. As a result, the total output produced by the photovoltaic power will decrease, thus reducing the efficiency of the conversion of solar energy to electricity [8]. Including a part of the photovoltaic panel will also cause this part not to be treated as a source but as an appliance. This is subsequently manifested by increasing the temperature of the shaded part. In extreme cases, it is even possible to heat up to damage the aforementioned part of the panel, which will cause the entire photovoltaic panel to be damaged. Therefore, in the design and construction of a photovoltaic power plant, it is important to prevent any partial shading of trees, surrounding buildings, power lines, etc. Also, the correct assignment of divisions between individual panels is an insignificant one. These distances are usually determined for the worst case scenario, which is the lowest position of the Sun above the horizon. For our territory (Slovakia), there is the smallest angle below which sun rays hit the surface of the earth in the winter period of about $17^{\circ}$ [8].

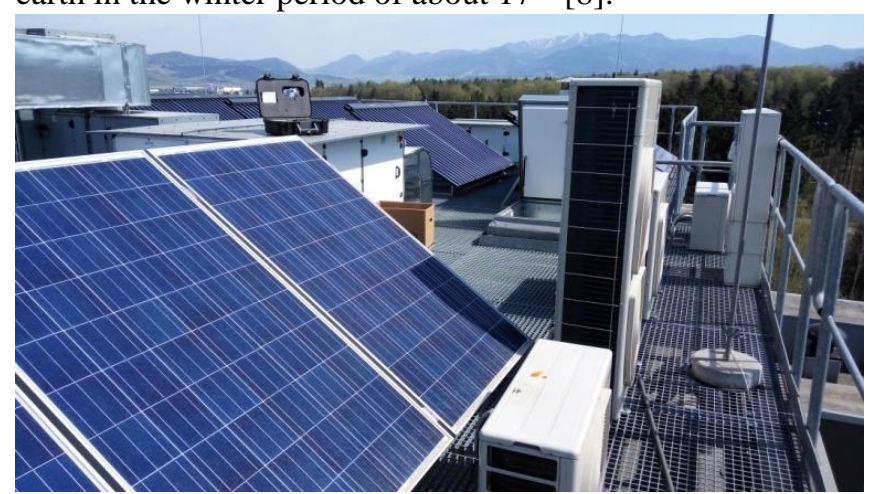

Fig. 3.2. Photo of a partially shielded SV60-255 photovoltaic panel.

\section{MEASUREMENT OF THE INFLUENCE OF LOCAL FACTORS ON PHOTOVOLTAIC PANELS}

The aim of the measurement was to verify the influence of the local factors on the PV panels and to find how much they affects the PV panels. The measurement was focused on polycrystalline and amorphous photovoltaic panels. The influence of surface pollution of photovoltaic panels on their performance was also monitored. Measurements were also performed on a broken and partially shaded photovoltaic panel. For the measurement was used volt-ampere method. Also, the temperature of the photovoltaic panels and the intensity of the sun's radiation were measured in all cases. For all the PV panels were made photos by infrared camera to find out how their individual parts are heated in specific cases. The measurement was carried out at the University of Žilina, on a Research Center of the University of Žilina.

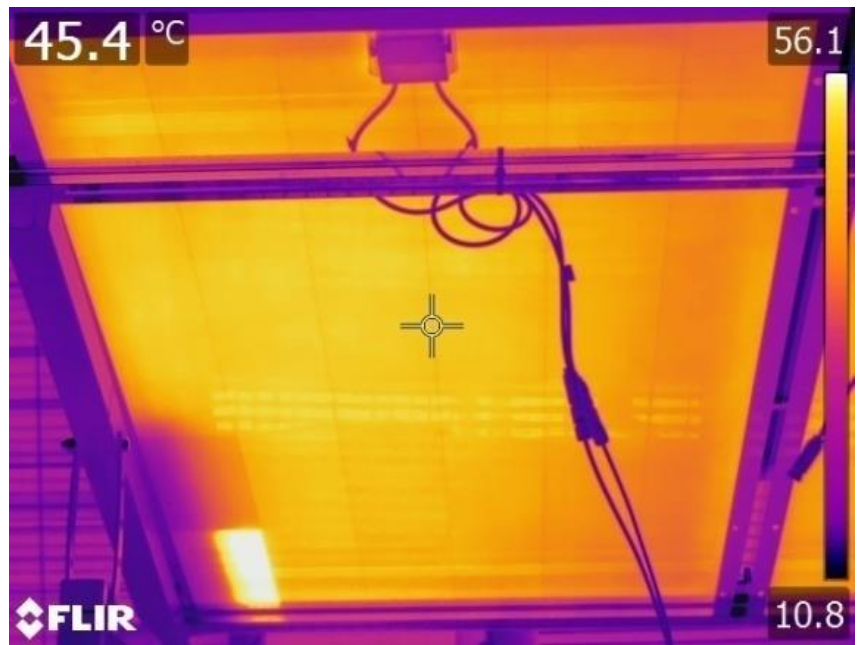

Fig. 4.1. Photo of a partially shielded SV60-255 photovoltaic panel from the back site made by infrared camera.

\section{A. Measurement of the Impact of partial shading of the Photovoltaic Panel}

This measurement was performed on a photovoltaic panel which was partly shielded by air condition (Fig. 3.2.). The purpose of this measurement was to find out how the partial 
shading of the photovoltaic panel works on its performance and heating. In the picture Fig. 4.1. there is the images of the SV60-255 PV panel made by infrared camera, while the panel is loaded with resistors. The volt-ampere characteristic, measured and calculated values are shown in picture Fig 4.2.

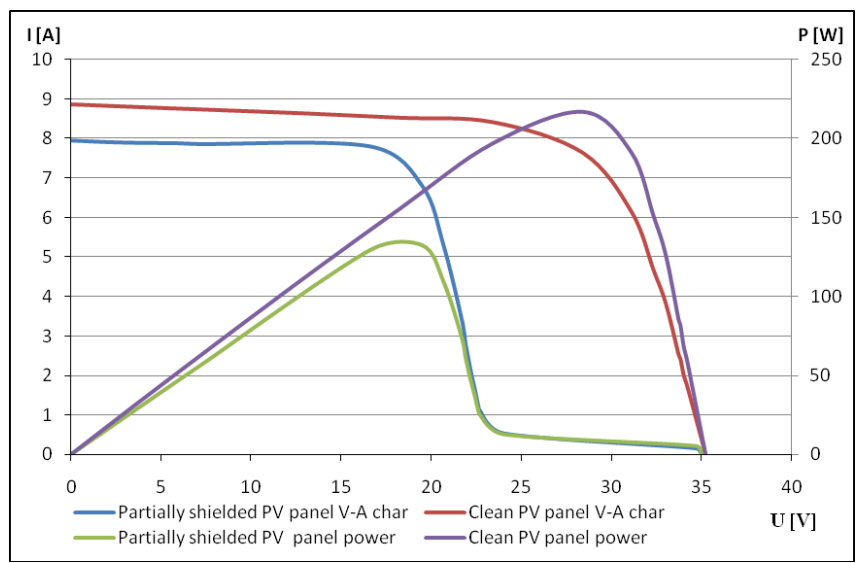

Fig. 4.2. V-A characteristics and power of a partially shielded SV60-255 photovoltaic panel.

\section{B. Measurement of a polluted and clean photovoltaic panel}

This measurement was aimed at monitoring the change in photovoltaic panel performance depending on its pollution. Panels were polluted by common impurities, dust that has settled on them since the installation of these panels. First, $\mathrm{V}-\mathrm{A}$ has been measured out by the characterization of the dirty panel from which the performance of this panel has been calculated. The same panel was cleaned and the measurement was repeated. The volt-ampere characteristic, measured and calculated values are shown in picture Fig. 3.4.

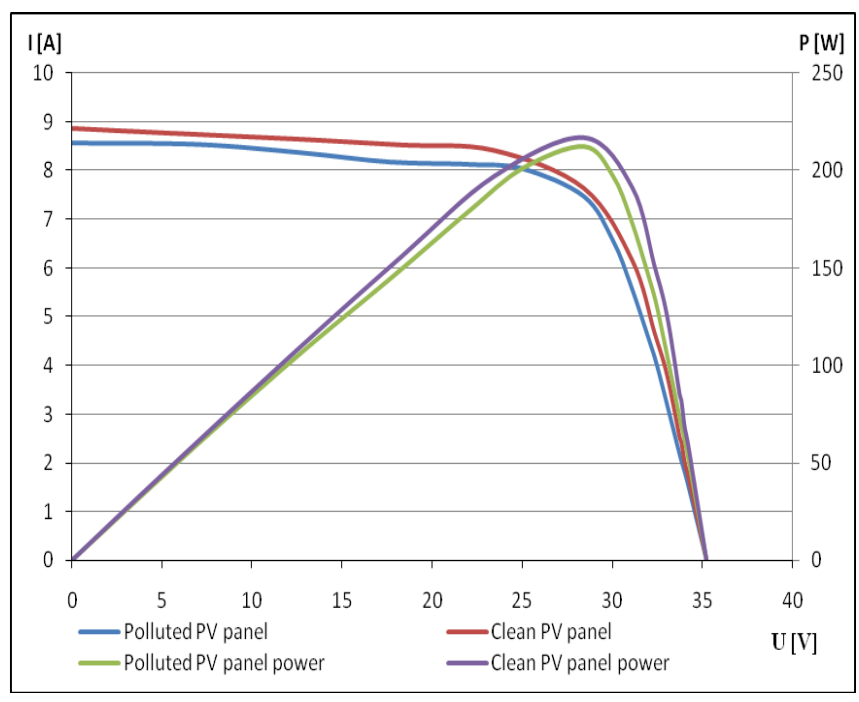

Fig. 4.3. V-A characteristics and power of a polluted SV60-255 photovoltaic panel.

\section{Measurement of cracked photovoltaic panel}

The last measurement was made on a cracked photovoltaic panel FS-277. We watched the impact of the PV panel cracks on its performance. We compared results with measurement on the same type of this PV panel which was in good condition. In FIG. 4.4 is a photo of the cracked panel.

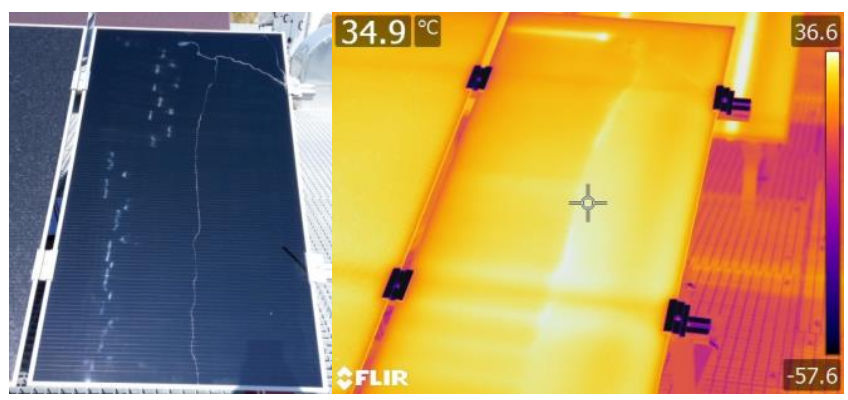

Fig. 4.4. Photos of a cracked photovoltaic panel FS-277.

It has been confirmed that the power of the cracked photovoltaic panel is up to $47.21 \%$ less than the performance of the same type of new PV panel. The limited operation of this cracked panel is also documented by infrared camera. Another fact is that damaged photovoltaic panel significantly reduces the performance of other panels involved in the same string.

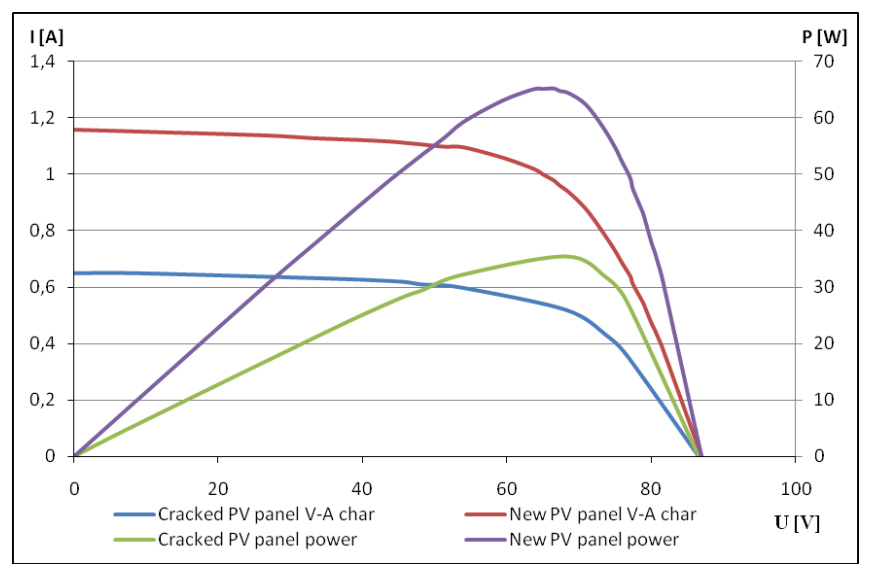

Fig. 4.3. V-A characteristics and power of FS-277 photovoltaic panel.

\section{CONCLUSION}

This study was done to use knowledge in a prediction system where it is important to know the real state of the photovoltaic power plant. As demonstrated, various local factors influence the performance of photovoltaic panels. The measurement was aimed at the influence of the panel's partial shading, pollution of the PV panel and PV panel damage on panel performance.

In the case of a partially-shielded polycrystalline panel, its performance was about $1 / 3$ less than power of the same type of the photovoltaic panel which was new. Near a big crack on the PV panel was considerably higher temperature which in extreme cases can lead to its damage. In view of this fact, the elimination of the partial screening of the panels is an important task in the design, construction, but also during the operation of the photovoltaic power plant.

The difference between the polluted and the clean photovoltaic panel was approximately $2 \%$. The difference in panel performance was not as significant as was predicted by other studies. Pollution of the panel is unlikely to be significant enough to show a great change in performance. The performance of the crack amorphous panel was up to $47 \%$ less than that of the same undamaged panel. In addition, the damaged photovoltaic panel permanently limits the 
performance of other panels in the same string. For this reason, when damaging the photovoltaic panel, it is necessary to replace it with a new, undamaged panel.

\section{REFERENCES}

[1] N. Santhosh, B. Prasad, "Efficiency improvement of a solar PV-panel through spectral sharing by combination of different panels", 2016 IEEE Students' Conference on Electrical, Electronics and Computer Science (SCEECS), Bhopal, India, 2016, 03, 5.-6., ISBN 978-1-4673-7918-2

[2] Y. Yamada, Y. Kurokawa, S. Kato, A. Yamada, "Silicon nanowire arrays passivated by Al2O3/TiO2stack layers", 2014 IEEE 40th Photovoltaic Specialist Conference (PVSC), Denver, CO, USA, 2014, 10, 8.-13., ISBN 978-1-4799-4398-2

[3] J. Xiao, L. Jiao, H. Zhu, R. Zhang, "Design of track control system in $P V^{\prime \prime}, 2010$ IEEE International Conference on Software Engineering and Service Sciences, Beijing, China, 2010, 07, 16.-18., ISBN 978-1-4244-6055-7

[4] Ch. Hajjaj, H. Amiry, R. Bendaoud, S. Yadir, A. Elhassnaoui, S. Sahnoun, M. Benhmida, A. EL Rhassouli, "Design of a new photovoltaic panel cooling system to optimize its electrical efficiency", 2016 International Renewable and Sustainable Energy Conference (IRSEC), Marrakech, Morocco, 2016, 11, 14.-17., ISBN 978-1-5090-5713-9

[5] M. S. Ashhab, O. Akash, "Experiment on PV panels tilt angle and dust", 2016 5th International Conference on Electronic Devices, Systems and Applications (ICEDSA), Ras Al Khaimah, United Arab Emirates, 2016, 12, 6.-8., ISBN 978-1-5090-5306-3

[6] A. K. Tripathi, Ch. S. N. Murthy, "Effect of shading on PV panel technology", 2017 International Conference on Energy, Communication, Data Analytics and Soft Computing (ICECDS), Chennai, India, 2017, 08, 1.-2., ISBN 978-1-5386-1887-5

[7] J. Dorda, (2017, March 30). "Vyplati sa investovat' do čistenia solárnych panelov? Prvé výsledky nemeckej štúdie to potvrdzujú!" [Online]. Available: http://www.solarnenovinky.sk/?spravy/ 2017112001/aktualne-vyplati-sa-investovat-do-cistenia-solarnych-pa nelov-prve-vysledky-nemeckej-studie-to-potvrdzuju

[8] P. Mastný. (2011). Obnovitelné zdroje energií (1st edition), Prague, Czech Republic, ISBN: ISBN 978-80-01-04937-2 [Paper book]. Available: https://www.mpo-efekt.cz/upload/7799f3fd595eeee1fa668 75530f33e8a/cvut-2-oze.pdf 